\title{
An Assessment of some Factors Influencing Scientific Research on Student's Competency Development According to CDIO Model in Vietnam
}

\author{
Nghiem Xuan Huy ${ }^{1, *}$, Tran Thi Hoai ${ }^{1}$, Ngo Tien Nhat ${ }^{1}$, \\ Nguyen Thi Tuyet Anh ${ }^{1}$, Dang Van Duy ${ }^{2}$, Nguyen Thi Thu $\mathrm{Ha}^{3}$ \\ ${ }^{l}$ VNU Institute for Education Quality Assurance, 144 Xuan Thuy, Cau Giay, Hanoi, Vietnam \\ ${ }^{2}$ People's Security Academy, 125 Tran Phu, Van Quan, Ha Dong, Hanoi, Vietnam \\ ${ }^{3}$ Ministry of Science and Technology, 13 Tran Duy Hung, Trung Hoa, Cau Giay, Hanoi, Vietnam \\ Received 15 March 2021 \\ Revised 04 April 2021; Accepted 07 April 2021
}

\begin{abstract}
The paper analyzes a number of factors related to scientific research activities including support policies; facilities, equipment and materials for scientific research; support from the universities to students in the development of four CDIO competencies (Conceive - Design Implement - Operate). The authors then evaluate the impact of the above factors on the student's competency development in the CDIO training model. The authors surveyed 1401 academic staff, 2306 students and conducted semi - structured interviews of 18 lecturers at 6 Vietnamese universities. The results show, from the most to the least influential groups of factors in the student competency development: facilities and equipment for practice, internship and scientific research activities, the university's support in the 4 CDIO phases and the policy matters, respectively. In general, all four students' competencies are assessed at a fairly high level and vary among universities. Specifically, the ability to form ideas was the highest rated, followed by the ability to design products, and the lowest rated competencies are to test and operate products in practice. Based on the findings, the authors proposed 6 solutions to improve student's competencies in the CDIO training model.
\end{abstract}

Keywords: Influence, Scientific Research, Student's Competency Development, CDIO.

\footnotetext{
${ }^{*}$ Corresponding author.

E-mail address: huynx@vnu.edu.vn

https://doi.org/10.25073/2588-1159/vnuer.4512
} 


\title{
Đánh giá ảnh hưởng của một số yếu tố trong nghiên cứu khoa học đến năng lực của sinh viên theo mô hình CDIO ở Việt Nam
}

\author{
Nghiêm Xuân Huy ${ }^{1, *}$, Trần Thị Hoài ${ }^{1}$, Ngô Tiến Nhật ${ }^{1}$, \\ Nguyễn Thị Tuyết Anh ${ }^{1}$, Đặng Văn Duy ${ }^{2}$, Nguyễn Thị Thu Hà3 \\ ${ }^{I}$ Viện Đảm bảo chất luợng giáo dục, Đại học Quốc gia Hà Nội, \\ 144 Xuân Thủy, Cầu Giấy, Hà Nội, Việt Nam \\ ${ }^{2}$ Học viện An ninh nhân dân, 125 Trần Phú, Văn Quán, Hà Đông, Hà Nội, Việt Nam \\ ${ }^{3}$ Bộ Khoa học và Công nghệ, 13 Trần Duy Hung, Trung Hòa, Cầu Giấy, Hà Nội, Việt Nam \\ Nhận ngày 15 tháng 3 năm 2021 \\ Chỉnh sửa ngày 04 tháng 4 năm 2021; Chấp nhận đăng ngày 07 tháng 4 năm 2021
}

\begin{abstract}
Tóm tắt: Bài viết phân tích một số yếu tố liên quan đến hoạt động nghiên cứu khoa học tại các trường đại học như các chính sách hố trợ sinh viên; cơ sở vật chất, trang thiết bị và học liệu phục vụ nghiên cứu khoa học; sự hỗ trợ của nhà trường đối với sinh viên trong việc phát triển bốn năng lực CDIO gồm các năng lực: Hình thành ý tưởng (Conceive), Thiết kế (Design), Triển khai (Implement) và Vận hành sản phẩm (Operate). Từ đó, nhóm tác giả đánh giá mức độ ảnh hưởng của các yếu tố trên đến năng lực của sinh viên trong đào tạo theo mô hình CDIO. Nhóm nghiên cứu đã khảo sát 1401 giảng viên, 2306 sinh viên và phỏng vấn bán cấu trúc 18 giảng viên tại 6 trường đại học Việt Nam. Kết quả cho thấy các yếu tố có ảnh hưởng nhiều nhất đến năng lực của sinh viên là nhóm yếu tố về cơ sở vật chất và trang thiết bị phục vụ thực hành, thực tập và nghiên cứu khoa học, tiếp đến là nhóm yếu tố về sự hỗ trợ của nhà trường trong bốn giai đoạn CDIO và ảnh hưởng ít nhất đến năng lực sinh viên là nhóm yếu tố về chính sách của nhà trường. Nhìn chung cả 4 năng lực của sinh viên đều được đánh giá ở mức khá cao và có sự phân biệt giữa các trường đại học, trong đó, năng lực hình thành ý tưởng được đánh giá cao nhất, tiếp theo là năng lực thiết kể sản phẩm, năng lực triển khai thử nghiệm và hoàn thiện sản phẩm, năng lực vận hành các sản phẩm trong thực tế được đánh giá thấp nhất. Từ kết quả phân tích mức độ ảnh hưởng của các yếu tố trên, nhóm nghiên cứu đã đề xuât 6 giải pháp cải tiến nhằm nâng cao năng lực của sinh viên trong đào tạo theo mô hình CDIO.
\end{abstract}

Tù khóa: Ảnh hưởng, Nghiên cứu khoa học, Năng lực sinh viên, CDIO.

\section{1. Đặt vấn đề}

Nghị quyết số 29-NQ/TW đã đề ra các nhiệm vụ, giải pháp cho đổi mới giáo dục đại học là "Tăng cường năng lực, nâng cao chất lượng và hiệu quả nghiên cứu khoa học, chuyển giao công nghệ của các cơ sở giáo dục đại học. Gắn kết chặt chẽ giữa đào tạo và nghiên cứu, giữa các cơ sở đào tạo với các cơ sở sản xuất, kinh doanh. Uu tiên đầu tư phát triển khoa học

\footnotetext{
* Tác giả liên hệ.

Địa chi email: huynx@vnu.edu.vn

https://doi.org/10.25073/2588-1159/vnuer.4512
}

cơ bản, khoa học mũi nhọn, phòng thí nghiệm trọng điểm, phòng thí nghiệm chuyên ngành, trung tâm công nghệ cao, cơ sở sản xuất thử nghiệm hiện đại trong một số cơ sở giáo dục đại học" [1]. Chất lượng và hiệu quả nghiên cứu khoa học trong các cơ sở giáo dục đại học có ảnh hưởng trực tiếp đến chất lượng đào tạo nguồn nhân lực. Sinh viên ngày càng tham gia nhiều hơn vào các hoạt động nghiên cứu khoa học cùng các giảng viên, các cán bộ nghiên cứu và từ đó hình thành nên các năng lực thiết yếu nhất. Trong bối cảnh cuộc Cách mạng công nghiệp 4.0, doanh nghiệp và các bên liên quan ngày càng đặt ra các yêu cầu khắt khe hơn đối 
với chất lượng nguồn nhân lực, trong đó đáng chú ý là bốn năng lực CDIO bao gồm: i) Hình thành ý tưởng (Conceive); ii) Thiết kế (Design); iii) Triển khai (Implement); và v) Vận hành sản phẩm (Operate). Để đáp ứng yêu cầu về nguồn nhân lực đó, một số trường đại học của Việt Nam đã xây dựng và triển khai các chương trình đào tạo theo tiếp cận CDIO - một cách tiếp cận phát triển năng lực người học thông qua gắn kết hoạt động đào tạo và nghiên cứu khoa học đang được nhiều nền giáo dục tiên tiến trên thế giới áp dụng trong quá trình cải tiến chất lượng các chương trình đào tạo. Trong mô hình đào tạo CDIO này, hoạt động nghiên cứu khoa học của sinh viên được các cơ sở giáo dục và đào tạo quan tâm đầu tư về chính sách, cơ sở hạ tầng và triển khai các hoạt động hỗ trợ sinh viên nghiên cứu khoa học,... nhằm giúp sinh viên hình thành bốn năng lực cần thiết. Để các cơ sở giáo dục đại học có cơ sở đầu tư, hỗ trợ sinh viên, cần triển khai nghiên cứu đánh giá mức độ ảnh hưởng của các yếu tố trong hoạt động nghiên cứu khoa học đến việc hình thành năng lực của sinh viên theo mô hình đào tạo CDIO.

\section{Tổng quan}

2.1. Yêu cầu về chất luợng nguồn nhân lực trong bối cảnh Cách mạng công nghiệp 4.0 và mô hình đào tạo CDIO

Bối cảnh của cuộc Cách mạng công nghiệp 4.0 đặt ra nhiều thách thức đối với xã hội nói chung và giáo dục đại học nói riêng, đặc biệt trong vấn đề đào tạo nguồn nhân lực. Vấn đề năng lực và phẩm chất của người học đáp ứng yêu cầu nhân lực 4.0 đã được trình bày trong nhiều báo cáo và tài liệu nghiên cứu trong nước và quốc tế $[2,3]$. Hecklau, Galeitzke, Flachs and Kohl, 2016 [4] giới thiệu 4 nhóm năng lực cần thiết cho người lao động 4.0 bao gồm: nhóm năng lực kĩ thuật (kiến thức, kĩ năng kĩ thuật, thực hiện thao tác quy trình, lập trình, công nghệ thông tin và đa phương tiện); nhóm kĩ năng phương pháp (sáng tạo, sáng nghiệp, giải quyết vấn đề, ra quyết định, kĩ năng phân tích, nghiên cứu và định hướng năng suất); nhóm kĩ năng xã hội (giao tiếp, ngôn ngữ, mạng lưới hợp tác, chuyển giao kiến thức, lãnh đạo) và nhóm kĩ năng cá nhân (sự linh hoạt, kiên trì, vượt khó, động cơ làm việc, chịu đựng áp lực, ...). Diễn đàn kinh tế thế giới (WEF, 2020) [5] mới đây đưa ra các điều chỉnh và cập nhật khung năng lực thế kỷ 21 , trong đó xác định 10 kĩ năng hàng đầu người lao động cần có trước năm 2025 bao gồm: i) Tư duy phân tích và đổi mới; ii) Học tập tích cực và có chiến lược; iii) Giải quyết vấn đề phức tạp; iv) Tư duy phản biện và phân tích; v) Sáng tạo, độc đáo và kiến tạo; vi) Năng lực lãnh đạo và sức ảnh hưởng đến xã hội; vii) Khả năng sử dụng công nghệ; viii) Thiết kế và lập trình công nghệ; ix) Khả năng phục hồi, chịu đựng căng thẳng và thích ứng linh hoạt; $x$ ) Lập luận, giải quyết vấn đề và lên ý tưởng. 10 kĩ năng trên thuộc 4 nhóm: nhóm năng lực giải quyết vấn đề (i, iii, iv, v, x); nhóm năng lực quản lý bản thân (ii, ix); nhóm năng lực làm việc hợp tác (vi) và nhóm năng lực sử dụng và phát triển công nghệ (vii, viii). Các nghiên cứu về kĩ năng trong thời đại 4.0 (BRICS, 2016) [6], cũng như các nghiên cứu kinh tế sáng tạo (creative economy) (Luckman, 2015) [7], các trường phái đại học hàng đầu thế giới (Marginson, 2013) [8], cho thấy, mỗi quốc gia, mỗi trường đại học cần tiến hành việc khảo sát, phân tích và lựa chọn cách thức phù hợp và hiệu quả nhất để xây dựng hệ thống phẩm chất và kĩ năng cần thiết cho người lao động theo các khung năng lực xác định. Điều này đồng thời đặt ra thách thức chính yếu mà các trường đại học đang phải đối mặt là làm thế nào để sinh viên có được các kiến thức, kĩ năng và thái độ mà doanh nghiệp và các bên liên quan khác mong muốn trong bối cảnh Cách mạng công nghiệp 4.0 [9].

Có thể thấy, yêu cầu đối với nguồn nhân lực trong bối cảnh Cách mạng công nghiệp 4.0 là rất toàn diện. Không chỉ đòi hỏi kĩ năng chuyên môn ở mức cao, Cách mạng công nghiệp 4.0 đòi hỏi người lao động phải có các năng lực nghiên cứu, năng lực xã hội, năng lực quản lý,... Quá trình đào tạo nguồn nhân lực chất lượng do đó cần có sự gắn bó, tích hợp chặt chẽ giữa hoạt động khoa học công nghệ và hoạt động đào tạo. Chỉ bằng cách gắn kết này, các năng lực của người học mới được hình thành và 
phát triển một cách bền vững, người học có khả năng thích ứng cao đối với các bối cảnh công việc khác nhau. Nhiều nghiên cứu đã chỉ ra các yếu tố liên quan tới hoạt động khoa học và công nghệ trong chương trình đào tạo giúp sinh viên hình thành và phát triển các năng lực thiết yếu đáp ứng yêu cầu của xã hội. Pascarella và Terenzini, 2005 [10] cho rằng việc sinh viên tham gia vào các dụ án nghiên cứu tại trường đại học có mối liên hệ với việc đạt được các kết quả mong đợi (về phẩm chất, kĩ năng, triển vọng học thuật,...) như sự kiên trì, cơ hội học tập ở bậc cao hơn và việc lựa chọn nghề nghiệp trong tương lai. Theo Hathaway và cộng sự (2002) [11], việc tham gia nghiên cứu ở bậc đại học có liên quan tích cực đến xác suất sinh viên theo học bậc sau đại học và tiếp tục các hoạt động nghiên cứu trong tương lai. Tương tự, Nnadozie và cộng sự (2001) [12] nhận thấy mối liên hệ tích cực giữa các kinh nghiệm trong hoạt động nghiên cứu ở bậc đại học đối với sự thành công của trong sự nghiệp của người học tốt nghiệp. Một số nghiên cứu khác cũng chỉ ra tác động của kinh nghiệm trong hoạt động nghiên cứu đối với sự phát triển và mức độ hài lòng của người học (Justice et al. 2007 [13]; Pascarella và Terenzini 2005 [10]; Volkwein và Carbone 1994 [14]). Với sú mệnh chuyên sâu về hoạt động nghiên cưu, các truờng đại hoc nghiên cúu (research universities) được cho là có lợi thế đáng kể trong việc cung cấp trải nghiệm nghiên cúu chất luợng cao cho sinh viên chua tốt nghiệp của họ (Gonzalez, 2001) [15]. Sinh viên tại nhiều trường đại học nghiên cứu, bao gồm Đại học Duke, Đại học Michigan, Đại học bang Pennsylvania, Đại học California tại cơ sở Berkeley,... có cơ hội làm việc cùng với các nhà khoa học có uy tín trong lĩnh vực. Để hỗ trợ người học tốt hơn trong việc hình thành, thiết kế, triển khai và vận hành sản phẩm nghiên cứu, nhiều trường đã quan tâm thúc đẩy tích cực các hoạt động nghiên cứu hơp tác với doanh nghiệp. Đây chính là hoạt động chuyển giao công nghệ - một hoạt động đặc trưng của đại học 4.0. Nhiều trường đại học đã chú trọng thúc đẩy các điều kiện hỗ trợ hoạt động nghiên cứu khoa học và ứng dụng, tạo hệ sinh thái đổi mới sáng tạo cho sinh viên. Các trường đại học như Mahidol (Thái Lan) (Wonglimpiyarat, 2016) [16] và Nam Kinh (Trung Quốc) (Lijie, 2017) [17] đang triển khai xây dựng hệ thống ươm tạo định hướng chuyển giao tri thức theo mô hình " 4 trong 1 " từ ý tưởng đến sáng tạo, đổi mới và sáng nghiệp. Các mô hình vườn ươm kinh doanh (business incubator) từ các phát minh, sáng chế và sở hữu trí tuệ của đại học và các mô hình khởi nghiệp, thiết lập các spin-off và doanh nghiệp xã hội (social enterprises) được triển khai một cách đồng bộ. Chuyển giao công nghệ từ đại học sáng nghiệp tới xã hội theo các cơ chế chính thức và không chính thức (Brown, 2016) [18] được các trường thực hiện bao gồm: i) Các nghiên cứu được tài trợ: Trường đại học nhận nguồn kinh phí thực hiện một dự án nghiên cứu thông qua một hợp đồng; ii) Bằng phát minh, sáng chế: Quyền hợp pháp được sử dụng các bằng sáng chế tài sản trí tuệ của trường đại học; iii) Công ty spin-off: Một doanh nghiệp mới được hình thành từ nghiên cứu của giảng viên hoặc từ bằng sáng chế của trường đại học; iv) Khởi nghiệp sinh viên: Được phát triển từ cựu sinh viên mà không dựa trên tài sản trí tuệ của trường đại học; và v) Tài nguyên con người: Tuyển dụng sinh viên từ trường đại học, đặc biệt là các sinh viên làm việc theo các dự án được tài trợ. Tại Việt Nam, các cơ sở giáo dục đại học đã nhận thức được rất rõ sự cần thiết và tầm quan trọng của sự gắn kết đào tạo - nghiên cứu - chuyển giao công nghệ và triển khai các giải pháp thúc đẩy việc hợp tác với doanh nghiệp trong nghiên cứu và đào tạo nhằm đáp ứng tốt hơn nhu cầu việc làm của xã hội $[19,20]$. Theo tác giả Bùi Đức Thọ (2017) [21], việc gắn kết đào tạo và nghiên cứu khoa học có thể triển khai thông qua việc gắn nghiên cứu với phát triển chương trình đào tạo; gắn nghiên cứu với nâng cao chất lượng bài giảng; gắn nghiên cứu với đào tạo, phát triển đội ngũ; gắn nghiên cứu với đào tạo một cách gián tiếp thông qua sáng tạo tri thức, chia sẻ tri thức, ứng dụng tri thức.

Mô hình đào tạo CDIO cho thấy sự gắn kết giữa các hoạt động đào tạo và nghiên cứu trong việc hỗ trợ sự hình thành và phát triển năng lực người học. Mô hình đào tạo theo tiếp cận năng lực này đến nay đã thu hút 120 trường thành 
viên thuộc 7 khu vực khác nhau trên toàn cầu sử dụng để xây dựng các chương trình đào tạo nhằm cải tiến chất lượng nguồn nhân lực [22]. Trước hết, mô hình CDIO đáp ứng yêu cầu về việc phát triển năng lực, kĩ năng của người lao động thông qua việc đào tạo sinh viên trở thành người kỹ sư toàn diện hiểu được cách thức Hình thành ý tưởng - Thiết kế - Triển khai - Vận hành những sản phẩm, quy trình và hệ thống kĩ thuật phức hợp, có giá trị gia tăng, trong môi trường hiện đại, làm việc theo nhóm [23, 24]. Cụ thể, CDIO bao gồm 4 giai đoạn bắt buộc để tạo ra một sản phẩm, quy trình hay hệ thống kĩ thuật, cũng là bốn năng lực cốt lõi mà sinh viên cần đạt được sau khi tốt nghiệp, bao gồm: hình thành ý tưởng về một sản phẩm, quy trình hoặc hệ thống (Conceive); thiết kế sản sản phẩm, quy trình hoặc hệ thống (Design); triển khai sản phẩm, quy trình hoặc hệ thống dựa trên bản thiết kế (Implement); và cuối cùng là vận hành sản phẩm, quy trình hoặc hệ thống đó (Operate). Tiếp cận CDIO cũng nhấn mạnh sinh viên tốt nghiệp sẽ thực hiện 4 năng lực trên trong môi trường làm việc theo nhóm (nhóm ở đây được hiểu không chỉ bó hẹp trong phạm vi nhóm người mà rộng hơn là quốc gia, toàn cầu). Một sinh viên giỏi không chỉ đòi hỏi khả năng sáng tạo, trách nhiệm cá nhân mà còn phải biết làm việc nhóm và giao tiếp hiệu quả trong quá trình thực hiện 4 năng lực C-D-I-O [25]. Mặt khác, 4 giai đoạn bắt buộc trên cũng tương ứng với quy trình của một hoạt động nghiên cứu và ứng dụng, hay rộng hơn là quy trình triển khai hoạt động khoa học và công nghệ trong trường đại học. Do đó, về bản chất, mối liên hệ giữa các hoạt động đào tạo và nghiên cứu trong các chương trình đào tạo theo tiếp cận CDIO là khá chặt chẽ. Tuy nhiển, vấn đề mối liên hệ tương hỗ giữa hoạt động nghiên cứu khoa học đối với việc phát triển năng lực người học trong mô hình đào tạo CDIO chưa thực sự được chú ý. Để làm rõ mối liên hệ trên, bài viết này sẽ phân tích một số yếu tố liên quan đến hoạt động nghiên cứu khoa học tại các trường đại học như các chính sách hỗ trợ sinh viên; cơ sở vật chất và trang thiết bị, học liệu phục vụ nghiên cứu khoa học; sự hỗ trợ của nhà trường đối với sinh viên trong việc phát triển 4 năng lực CDIO (gồm năng lực hình thành ý tưởng, thiết kế, triển khai và vận hành), đánh giá mức độ ảnh hưởng của các yếu tố trên đến năng lực của sinh viên trong đào tạo theo mô hình CDIO, từ đó đề xuất các giải pháp cải tiến nhằm nâng cao năng lực của sinh viên trong đào tạo theo mô hình CDIO.

Như vậy, có thể thấy, để nâng cao chất lượng của các sản phẩm đào tạo đáp ứng yêu cầu về nguồn nhân lực 4.0, các trường đại học trên thế giới đã chú trọng tới các yếu tố liên quan tới hoạt động khoa học và công nghệ để hỗ trợ người học. CDIO là một mô hình đào tạo theo tiếp cận năng lực có khả năng thúc đẩy sự gắn kết giữa nghiên cứu khoa học và hoạt động đào tạo, nhờ đó tăng tính hiệu quả trong việc phát triển nguồn nhân lực đáp ứng yêu cầu thực tiễn.

\subsection{Hoạt động nghiên cúu khoa học trong các truòng đại hoc}

Hầu hết các trường đại học ở Việt Nam, các hoạt động nghiên cứu khoa học thể hiện bằng việc thực hiện các chương trình, dự án, đề tài nghiên cứu khoa học các cấp, nghiên cứu và ứng dụng công nghệ, biên soạn giáo trình, bài giảng, các tài liệu chuyên khảo,... Trường đại học có đặc thù vừa là cơ sở đào tạo nguồn nhân lực, vừa là cơ sở nghiên cứu khoa học đầu ngành. Đây là nơi có một đội ngũ các nhà khoa học có trình độ chuyên môn cao của đất nước, họ vừa làm công tác giảng dạy, vừa làm công tác nghiên cứu khoa học và góp phần tạo ra cái mới, loại bỏ cái cũ, lạc hậu. Hoạt động nghiên cứu khoa học trong trường đại học có những nét đặc thù [26] như:

i) Hoạt động nghiên cứu khoa học trong các trường đại học luôn gắn liền với nhu cầu đào tạo và sản xuất, hình thành nên mối liên hệ nghiên cứu khoa học - đào tạo - sản xuất. Hoạt động nghiên cứu khoa học trong nhà trường luôn gắn liền với đào tạo, sản xuất và đổi mới. Cuộc Cách mạng công nghiệp 4.0 đã tác động mạnh mẽ đến ngành nghề, nhiều ngành đã không còn nhu cầu về nhân lực mà được thay thế bởi máy móc, công nghệ. Ngược lại, tiến bộ của khoa học và công nghệ thúc đẩy phân công lao động xã hội, làm xuất hiện những ngành sản xuất mới, làm thay đổi ngành nghề đào tạo, làm hình thành ngành đào tạo mới và tác động lại 
khoa học và công nghệ phát triển. Hoạt động nghiên cứu khoa học góp phần nâng cao chất lượng đào tạo, nhất là phát triển, vận dụng lý luận vào thực tiễn. Trong quá trình học tập, việc tham gia hoạt động khoa học và công nghệ làm cho sinh viên bước đầu làm quen với nghiên cứu khoa học, giúp họ có điều kiện lĩnh hội được các kiến thức mới mang tính hệ thống, đồng thời biết cách vận dụng lý thuyết vào giải quyết các vấn đề của thực tiễn. Qua đó, sinh viên được rèn luyện kĩ năng và phương pháp phân tích khoa học hết sức cần thiết cho công việc khi tốt nghiệp. Nghiên cứu khoa học - đào tạo - sản xuất có mối quan hệ chặt chẽ nhằm chuẩn bị kiến thức, định hướng cho nội dung giảng dạy nhằm làm cho giáo dục luôn đi đầu và không bị lạc hậu. Nhiều nghiên cứu thực tiễn cho thấy, tri thức khoa học đã góp phần lớn vào việc phát hiện, dự báo các nhu cầu mới, từ đó thúc đẩy hình thành các ngành sản xuất mới, ngành đào tạo mới, đồng thời, đó cũng là động lực thúc đẩy mạnh mẽ đối với sự phát triển của nghiên cứu khoa học và sản xuất. Việc kết hợp 3 yếu tố trên còn giúp nâng cao chất lượng đội ngũ giảng viên và cán bộ nghiên cứu của trường đại học, đồng thời sử dụng hiệu quả cơ sở vật chất, trang thiết bị của nhà trường và góp phần hoàn thiện cơ sở vật chất phục vụ cho hoạt động nghiên cứu khoa học, đào tạo;

ii) Sản phẩm của hoạt động nghiên cứu khoa học trong trường đại học vừa đáp ứng nhu cầu của xã hội, vừa phát triển nguồn nhân lực khoa học. Khác với các đơn vị nghiên cứu khoa học khác trong xã hội, sản phẩm hoạt động nghiên cứu khoa học trong các trường đại học đa dạng hơn. Đối với các đơn vị như Viện nghiên cứu, trung tâm nghiên cứu không thuộc trường đại học, sản phẩm nghiên cứu khoa học chủ yếu là các sản phẩm mới, sáng chế, những quy trình công nghệ,... nhằm phục vụ cho nâng cao năng suất lao động hoặc cải tiến ra những sản phẩm mới. Trong khi đó, đối với các trường đại học, sản phẩm nghiên cứu khoa học phục vụ trực tiếp cho quá trình đào tạo, là hệ thống mục tiêu, chương trình, tài liệu phục vụ cho công tác đào tạo và nghiên cứu. Đội ngũ giảng viên, chương trình, giáo trình đóng vai trò lớn trong nâng cao chất lượng đào tạo nguồn nhân lực, phát triển năng lực cho sinh viên. Qua các hoạt động nghiên cứu khoa học, trình độ, năng lực của giảng viên, sinh viên được hoàn thiện, phát triển, sản phẩm nghiên cứu khoa học được quay trở lại phục vụ trực tiếp vào công tác đào tạo nguồn nhân lực cho xã hội;

iii) Hoạt động nghiên cứu khoa học được thực hiện bởi đa dạng các chủ thể nghiên cứu, có khả năng đáp ứng được yêu cầu phát triển của tất cả các lĩnh vực của đời sống xã hội. Tham gia nghiên cứu khoa học trong nhà trường không chỉ có Hội đồng khoa học và đào tạo, các nhà khoa học, nghiên cứu sinh và học viên cao học mà có sự tham gia mạnh mẽ của đội ngũ sinh viên. Hằng năm, có hàng trăm công trình sinh viên nghiên cứu khoa học được Bộ Giáo dục và Đào tạo trao giải, đây chỉ là con số rất nhỏ trong hàng nghìn đề tài sinh viên nghiên cứu khoa học trong cả nước [27]. Chính trong hoạt động nghiên cứu khoa học và phát triển công nghệ, sinh viên của trường đại học có điều kiện phát triển năng lực, kĩ năng tổ chức nghiên cứu, từ việc hình thành ý tưởng, thiết kế, triển khai và vận hành trong thực tế để đánh giá hiệu quả của các biện pháp đã đề xuất, gắn lý luận với thực tiễn, chủ động kết nối giữa nhà trường với doanh nghiệp, giữa các ngành với nhau. Thế mạnh của trường đại học là có lực lượng lớn sinh viên, đặc biệt là học viên nghiên cứu sinh, cao học, cán bộ, chuyên viên của các đơn vị thực tế tham gia nghiên cứu khoa học; đồng thời, trường đại học còn thường xuyên có các hoạt động nghiên cứu khoa học phối hợp với các trường đại học ở nước ngoài, hoạt động thực tế tại các doanh nghiệp và đơn vị tuyển dụng lao động để phát triển hệ thống tri thức, cập nhật những kiến thức mới. Việc tham gia hoạt động nghiên cứu khoa học trong quá trình học tập giúp sinh viên lĩnh hội được các kiến thức mới mang tính hệ thống, đồng thời biết cách vận dụng lý thuyết vào giải quyết các vấn đề của thực tiễn. Bởi vậy, họ rèn luyện được kĩ năng và phương pháp phân tích khoa học hết sức thiết thực cho công việc sau khi tốt nghiệp. Ngoài ra, việc mở rộng hoạt động sinh viên nghiên cứu khoa học, cùng với sự tham gia của các nhà nghiên cứu, nhà khoa học, đơn vị sử dụng lao động còn giúp nhà trường mở rộng được các 
lĩnh vực hoạt động, tăng cường các hoạt động nghiên cứu, tổng kết thực tiễn, tăng mối quan hệ gắn kết giữa nhà trường với doanh nghiệp.

Có thể nói, hoạt động nghiên cứu khoa học trong các trường đại học diễn ra thường xuyên, liên tục và có sự tham gia củanhiều cán bộ nghiên cứu, sinh viên, cán bộ thực tiễn. Ba chủ thể này đóng vai trò quan trọng trong việc hình thành mối liên hệ nghiên cứu khoa học - đào tạo - sản xuất, nâng cao chất lượng đào tạo, định hướng phát triển năng lực của sinh viên đáp ứng nhu cầu của nhà tuyển dụng.

\subsection{Năng lực của sinh viên trong đào tạo theo mô hìn CDIO}

Cuộc Cách mạng công nghiệp 4.0 đặt ra thách thức hiện nay là cần thay đổi phương thức đào tạo để đáp ứng yêu cầu của các bên liên quan ngoài trường đại học và cải tiến chương trình, phương pháp giáo dục, bản chất là để thay đổi văn hóa giáo dục. Mô hình đào tạo CDIO đáp ứng thách thức này thông qua việc đào tạo sinh viên trở thành người toàn diện, hiểu được cách thức, quy trình và hệ thống kĩ thuật phức hợp phù hợp với từng ngành nghề. Điểm nổi bật của mô hình này là: Giáo dục dựa trên các mục tiêu của chương trình học và chuẩn đầu ra của sinh viên được nêu rõ ràng nhờ vào sự góp ý của các bên liên quan; chuẩn đầu ra của sinh viên được đáp ứng bằng việc xây dựng một chuỗi kinh nghiệm học tập tích hợp, trong đó có một số kinh nghiệm mang tính trải nghiệm, nghĩa là, tạo điều kiện cho sinh viên trải nghiệm những tình huống mà người học có thể gặp phải trong công việc sau khi tốt nghiệp. Việc xây dựng một chuỗi kinh nghiệm học tập thích hợp sẽ tạo ra tác dụng kép, vừa đào tạo các kĩ năng, vừa hỗ trợ việc lĩnh hội kiến thức chuyên sâu.

Chuẩn đầu ra của chương trình đào tạo cần được xây dựng dựa trên nhu cầu xã hội, yêu cầu của từng ngành nghề, được lấy ý kiến của các bên liên quan và có thể dễ dàng đo lường và đánh giá được. Ma trận chuẩn đầu ra phản ánh mối liên hệ chặt chẽ giữa những học phần trong chương trình đào tạo với yêu cầu người học cần đạt được về kiến thức, kĩ năng, mức tự chủ và trách nhiệm.
Việc tham gia vào quá trình tư duy về các khái niệm, đặc biệt là các ý tưởng mới giúp sinh viên phát huy năng lực nghiên cứu, làm tăng động lực học tập của sinh viên đáp ứng các yêu cầu về chuẩn đầu ra của chương trình đào tạo và hình thành thói quen học tập suốt đời. Các phương pháp học tập chủ động thu hút sự tham gia của sinh viên vào các hoạt động tư duy và giải quyết vấn đề. Phương pháp dạy - học tích cực được thể hiện qua việc tổ chức các hoạt động như thảo luận, seminar, tranh luận, demo, hoặc làm việc nhóm và báo cáo kết quả nghiên cứu. Qua đó, hình thức học tập trải nghiệm được hình thành thông qua việc sinh viên đảm nhận các vai trò mô phỏng thực hành kĩ thuật nghề nghiệp, thực hành tình huống,...

Ở Việt Nam, nhiều trường đại học đào tạo về kĩ thuật, công nghệ thông tin, truyền thông và một số trường đại học thuộc các lĩnh vực khác đã vận dụng hiệu quả mô hình CDIO vào tổ chức đào tạo. Đại học Quốc gia Thành phố Hồ Chí Minh là đơn vị tiên phong của Việt Nam tham gia Hiệp hội quốc tế CDIO và trở thành thành viên thứ 56 của Hiệp hội $\mathrm{CDIO}$ Thế giới [29]. Nhận thấy được hiệu quả từ việc áp dụng trên, các cơ sở giáo dục đại học ở Việt Nam đã dần tiếp cận bằng nhiều hình thức khác nhau để khai thác, triển khai, áp dụng mô hình CDIO vào các hoạt động đào tạo. Bước đầu, hầu hết các trường tiếp cận mô hình $\mathrm{CDIO}$ trong xây dựng chuẩn đầu ra, phát triển chương trình đào tạo và tổ chức tập huấn cho nhóm triển khai dự án, nâng cao nhận thức về CDIO cho đội ngũ giảng viên, cán bộ quản lý nhằm thay đổi cách thức quản lý và phương pháp giảng dạy theo hướng dạy học tích cực, chủ động, tiếp cận học chế trải nghiệm. Tiếp theo, các trường triển khai chương trình đào tạo vào thực tiễn, thường xuyên quán triệt giảng viên chú trọng đến phương pháp dạy học, đổi mới phương pháp kiểm tra, đánh giá cho phù hợp với chuẩn đầu ra CDIO.

Kết quả đạt được, nhiều chương trình đào tạo đã được xây dựng theo tiếp cận CDIO, trong đó, chuẩn đầu ra được thiết kế với định hướng rõ ràng, cụ thể. 


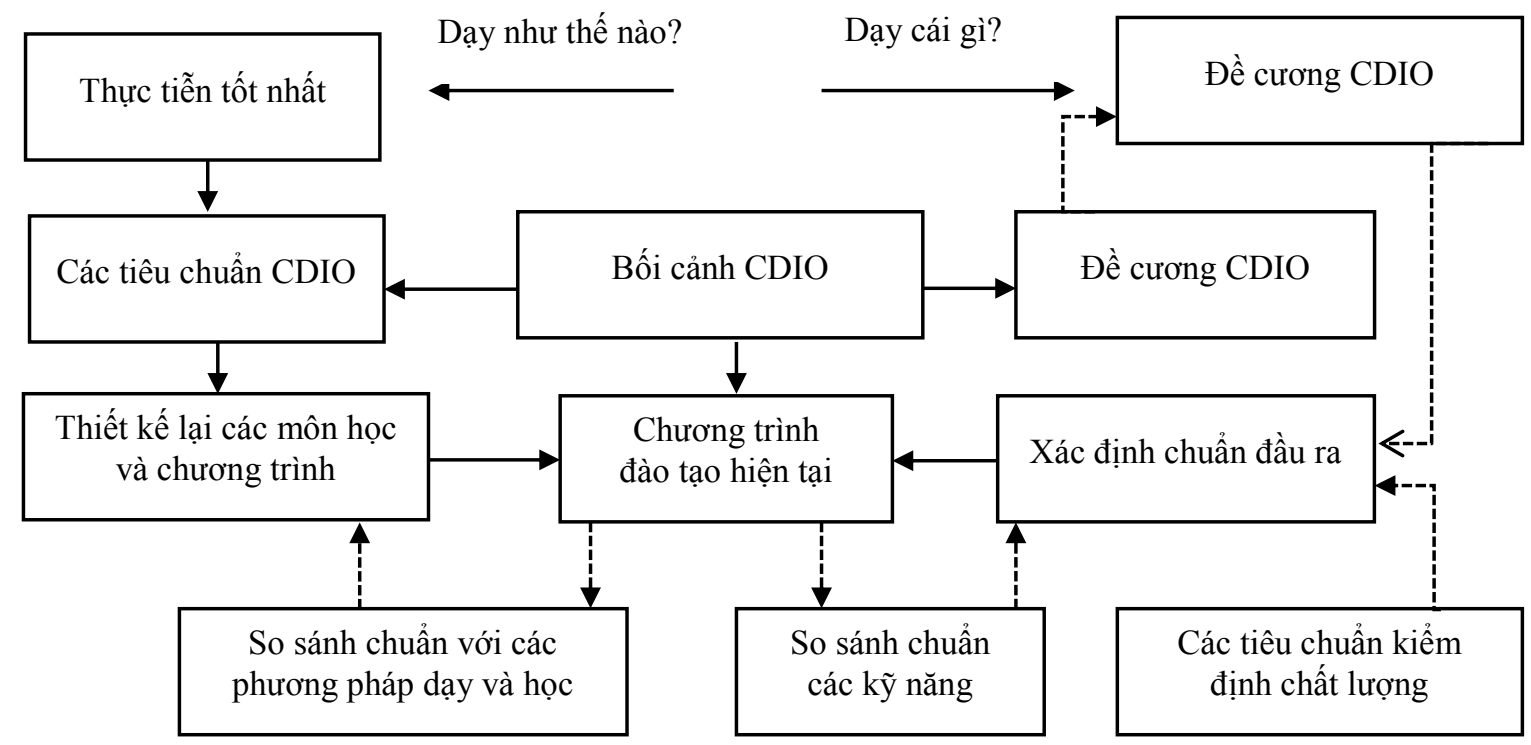

Hình 1. Mô hình đào tạo tiếp cận CDIO.

Nguồn: Cải cách và xây dựng chương trình đào tạo kỹ thuật theo phương pháp tiếp cận CDIO (Hồ Tấn Nhựt, Đoàn Thị Minh Trinh biên dịch, 2008) [28].

Phương pháp dạy và học có nhiều đổi mới, sáng tạo, phương pháp đánh giá theo quá trình được triển khai rộng, chất lượng nhiều trường được đảm bảo. Ngân hàng câu hỏi được xây dựng phù hợp với yêu cầu trong chuẩn đầu ra. Hệ thống cơ sở vật chất, trang thiết bị từng bước được hoàn thiện, phục vụ dạy và học hiệu quả. Sản phẩm đào tạo đáp ứng chuẩn đầu ra theo CDIO có kiến thức cơ bản, có năng lực, phẩm chất phù hợp với bối cảnh, có khả năng thực hành, vận hành tốt, đáp ứng được yêu cầu của người tuyển dụng lao động.

Bởi vậy, theo tiếp cận mô hình $\mathrm{CDIO}$, năng lực của sinh viên có thể được hình thành như sau:

i) Năng lực hình thành ý tưởng (Conceive) gồm: vận dụng được các định nghĩa, khái niệm, kiến thức đã học làm nền tảng cơ bản; có năng lực phân tích, nhận định về bối cảnh kinh tế, xã hội và bối cảnh của ngành nghề; sinh viên tốt nghiệp phải hình thành được ý tưởng về: chiến lược, kế hoạch, nhu cầu của xã hội và nhà tuyển dụng, mục tiêu, đối thủ cạnh tranh. Cụ thể hơn, sinh viên phải có năng lực hình thành ý tưởng thiết kế, mô hình hoá ý tưởng, quản lý, nắm vững các quy luật như: ý tưởng về cấu trúc, chương trình, phần mềm, sơ đồ,... hay có thể nói là hình thành một bức tranh tổng quát sau khi tốt nghiệp đối với từng ngành nghề được đào tạo. Trong hoạt động nghiên cứu khoa học, năng lực hình thành ý tưởng, định hướng được một vấn đề để xây dựng tên đề tài là yếu tố quan trọng, xuyên suốt của quá trình;

ii) Năng lực thiết kế (Design) gồm: thiết kế sơ bộ và thiết kế chi tiết. Thiết kế sơ bộ có thể là chủ đề nghiên cứu, dàn ý, đề cương hoặc một bản vẽ phác thảo, các yêu cầu hoặc một báo cáo được thể hiện theo tư duy của sinh viên. Thiết kế chi tiết là việc cụ thể hoá các nội dung trong thiết kế sơ bộ như thiết kế các bản vẽ cụ thể, mô phỏng, hoặc xây dựng được đề cương chi tiết, thiết kế được các câu hỏi phỏng vấn, thảo luận trong nghiên cứu khoa học. Năng lực thiết kế yêu cầu sinh viên phải hiểu và vận dụng kiến thức đã được trang bị để xây dựng, phác thảo, cụ thể ý tưởng về sản phẩm;

iii) Năng lực triển khai (Implement) gồm: chế tạo chi tiết và tích hợp, thử nghiệm hệ thống. Năng lực này của sinh viên có khả năng hiện thực hoá những bản vẽ, chương trình, dự án đã thiết kế thành hiện thực, nó có thể bao gồm: chế tạo phần cứng, lập trình phần mềm, tạo ra những sản phẩm như mong muốn. Tích 
hợp và thử nghiệm hệ thống là năng lực thử nghiệm các sản phẩm, thử nghiệm phần mềm trên đại diện một số đối tượng nghiên cứu trước khi triển khai rộng rãi. Trong hoạt động nghiên cứu khoa học, sau khi xây dựng được công trình nghiên cứu khoa học, trong đó, các giải pháp, phát minh, sáng chế cần được đưa vào thử nghiệm một cách hệ thống để đánh giá hiệu quả trong quá trình thực hiện;

iv) Năng lực vận hành (Operate) gồm năng lực hỗ trợ và năng lực phát triển. Hỗ trợ là năng lực thúc đẩy tiêu thụ sản phẩm, phân phối sản phẩm và bảo hành. Phát triển là năng lực đánh giá, cải tiến, hoàn thiện hệ thống, mở rộng hoặc loại bỏ sản phẩm. Năng lực phát triển cũng là sáng tạo các dự án, phương án mới để tiếp tục nối vòng xoay CDIO như hiện nay. Trong đó, phát triển cũng là năng lực quan trọng giúp năng lực hình thành ý tưởng tiếp tục được phát triển lên một bậc.

Như vậy, hầu hết các năng lực trên đều nhằm giúp sinh viên thích ứng với môi trường công việc sau khi tốt nghiệp, đồng thời phản ứng nhanh với vòng đời của sản phẩm. Mỗi nhóm năng lực theo CDIO đều có mối quan hệ chặt chẽ, mang tính quy trình. Ngoài kiến thức được trang bị, để hình thành các năng lực trên theo CDIO, sinh viên cần trang bị, rèn luyện các kĩ năng như: kĩ năng làm việc, vận hành nhóm, giao tiếp, các kĩ năng cá nhân và kĩ năng trong nghề nghiệp.

\section{Phương pháp nghiên cứu}

Nhóm tác giả sử dụng phương pháp nghiên cứu tài liệu trong nước và quốc tế liên quan đến hoạt động nghiên cứu khoa học và năng lực của sinh viên cũng như mô hình đào tạo CDIO tại các trường đại học.

Nhóm nghiên cứu đã khảo sát 1401 giảng viên và 2306 sinh viên về hoạt động nghiên cứu khoa học của sinh viên, các điều kiện đảm bảo chất lượng hoạt động nghiên cứu khoa học, năng lực của sinh viên trong đào tạo theo mô hình $\mathrm{CDIO}, \ldots$ Ngoài ra, nhóm nghiên cứu đã phỏng vấn bán cấu trúc 18 giảng viên và cán bộ quản lý tại 6 trường đại học Việt Nam để tìm ra các yếu tố ảnh hưởng từ hoạt động khoa học công nghệ đến năng lực của sinh viên. Trong 18 giảng viên và cán bộ quản lý (6 phó giáo sư, 11 tiến sĩ, 1 thạc sĩ) có 12 giảng viên đồng thời là cán bộ quản lý ở các vị trí: phó hiệu trưởng, chủ nhiệm khoa, phó chủ nhiệm khoa, chủ nhiệm bộ môn của các trường đại học Việt Nam.

Bảng 1. Mẫu khảo sát

\begin{tabular}{|l|l|l|l|l|l|l|l|}
\hline & $\begin{array}{l}\text { Đại học } \\
\text { Quốc Gia } \\
\text { Hà Nội }\end{array}$ & $\begin{array}{l}\text { Trường Đại học Khoa } \\
\text { học Tự nhiên - Đại } \\
\text { học Quốc gia Thành } \\
\text { phố Hồ Chí Minh }\end{array}$ & $\begin{array}{l}\text { Trường } \\
\text { Đại học } \\
\text { Cần Thơ }\end{array}$ & $\begin{array}{l}\text { Trường } \\
\text { Đại họcc } \\
\text { Quy } \\
\text { Nhơn }\end{array}$ & $\begin{array}{l}\text { Trường Đại } \\
\text { học Sư } \\
\text { phạm Thái } \\
\text { Nguyên }\end{array}$ & $\begin{array}{l}\text { Trường Đại } \\
\text { học Bách } \\
\text { Khoa Hà Nội }\end{array}$ & Tổng \\
\hline $\begin{array}{l}\text { Giảng } \\
\text { viên }\end{array}$ & 352 & 350 & 200 & 99 & 199 & 201 & 1401 \\
\hline $\begin{array}{l}\text { Sinh } \\
\text { viên }\end{array}$ & 498 & 504 & 400 & 401 & 106 & 397 & 2306 \\
\hline Tổng & 850 & 854 & 600 & 500 & 305 & 598 & 3707 \\
\hline
\end{tabular}

Nguồn: Dữ liệu khảo sát thuộc đề tài khoa học và công nghệ độc lập cấp Quốc gia, mã số ĐTĐLXH - 12/18.

Chọn mẫu: 6 trường đại học được lựa chọn đại diện cho ba miền Bắc, Trung, Nam; các trường đại học tại các thành phố lớn, thành phố vừa và nhỏ; các trường đại học có quy mô tuyển sinh lớn và các trường có quy mô tuyển sinh trung bình.
Quy trình thực hiện khảo sát: Khảo sát được triển khai thông qua phiếu hỏi và thực hiện khảo sát trực tiếp tại 6 đơn vị.

Thời gian tiến hành khảo sát: Từ tháng 6/2020 tới tháng 01/2021. 
Phân tích dữ liệu: Dữ liệu được phân tích bằng phần mềm SPSS. Ngoài thống kê mô tả, các tác giả phân tích thêm về hệ số tương quan Pearson để làm rõ mối quan hệ của các biến độc lập (các điều kiện đào tạo và nghiên cứu) và các biến phụ thuộc (năng lực của sinh viên dựa theo $\mathrm{CDIO}$ ).

Bộ công cụ khảo sát: Nhóm tác giả đã xây dựng bộ công cụ khảo sát lấy ý kiến của giảng viên và sinh viên bao gồm 14 câu hỏi sử dụng thang Likert 5 bậc, trong đó:
Biến độc lập: 10 câu hỏi lấy ý kiến đối tượng khảo sát về điều kiện về sự hỗ trợ của nhà trường với sinh viên trong các hoạt động gắn kết đào tạo và hoạt động khoa học công nghệ theo CDIO. Độ tin cậy của 10 câu hỏi này được tính theo Cronbach Alpha là 0,885 (độ tin cậy cao) và tương quan giữa các biến với biến tổng đều ở trên mức 0,4 cho thấy các biến đều có ảnh hưởng tới điều kiện chung và có thể sử dụng trong các phân tích tiếp theo.

Bảng 2. Mức độ tin cậy của thang đo điều kiện về sự hỗ trợ của nhà trường với sinh viên trong các hoạt động gắn kết đào tạo và hoạt động khoa học công nghệ theo CDIO

\begin{tabular}{|c|c|c|c|}
\hline Tiêu chí & Điều kiện & $\begin{array}{l}\text { Tương quan } \\
\text { với biến tổng }\end{array}$ & $\begin{array}{l}\text { Hệ số Cronbach's } \\
\text { Alpha nếu loại } \\
\text { bỏ biến }\end{array}$ \\
\hline Điều kiện 1 & Quỹ hỗ trợ sinh viên tham gia nghiên cứu khoa học & 0,705 & 0,863 \\
\hline Điều kiện 2 & $\begin{array}{l}\text { Chính sách hỗ trợ sinh viên tham gia nghiên cứu } \\
\text { khoa học }\end{array}$ & 0,702 & 0,864 \\
\hline Điều kiện 3 & $\begin{array}{l}\text { Chính sách hỗ trợ sinh viên tham gia thực hành, thực } \\
\text { tập tại các doanh nghiệp }\end{array}$ & 0,664 & 0,866 \\
\hline Điều kiện 4 & Không gian học tập, thực hành, nghiên cứu & 0,490 & 0,879 \\
\hline Điều kiện 5 & Cơ sở vật chất và trang thiết bị & 0,520 & 0,877 \\
\hline Điều kiện 6 & Học liệu phục vụ học tập, thực hành và nghiên cứu & 0,510 & 0,877 \\
\hline Điều kiện 7 & $\begin{array}{l}\text { Sự hỗ trợ của nhà trường trong việc giúp sinh viên } \\
\text { hình thành ý tưởng nghiên cứu }\end{array}$ & 0,650 & 0,868 \\
\hline Điều kiện 8 & $\begin{array}{l}\text { Sự hỗ trợ của nhà trường trong việc giúp sinh viên } \\
\text { phân tích, đánh giá ý tưởng/sản phẩm khoa học } \\
\text { công nghệ }\end{array}$ & 0,540 & 0,879 \\
\hline Điều kiện 9 & $\begin{array}{l}\text { Sự hỗ trợ của nhà trường trong việc giúp sinh } \\
\text { viên phát triển và hoàn thiện sản phẩm khoa học } \\
\text { công nghệ }\end{array}$ & 0,698 & 0,864 \\
\hline Điều kiện 10 & $\begin{array}{l}\text { Sự hỗ trợ của nhà trường trong việc giúp sinh viên } \\
\text { thương mại hóa/chuyển giao sản phẩm }\end{array}$ & 0,657 & 0,867 \\
\hline \multicolumn{2}{|l|}{ Độ tin cậy } & \multicolumn{2}{|l|}{0,882} \\
\hline
\end{tabular}

Nguồn: Dữ liệu khảo sát thuộc đề tài khoa học và công nghệ độc lập cấp Quốc gia, mã số ĐTĐLXH - 12/18.

Nhóm nghiên cứu đã sử dụng phương pháp phân tích nhân tố khám phá (EFA) nhằm phân chia 10 câu hỏi về điều kiện hỗ trợ của nhà trường với sinh viên vào các nhóm nhân tố giúp xác định rõ hơn các yếu tố ảnh hưởng tới năng lực của sinh viên theo mô hình CDIO. Kết quả cho thấy: hệ số KMN của 10 item có giá trị $0,982>0,5$ chứng tỏ sự thích hợp của EFA và 10 item có thể chia thành 3 nhóm (với các item trong nhóm đều có hệ số tải nhân tố lớn hơn 0,8 - với hệ số tải nhân tố lớn hơn 0,7 được coi là rất tốt) như Bảng 3 dưới đây: 
Từ nội hàm của các điều kiện, nhóm nghiên cứu có thể đặt tên cho 3 nhóm điều kiện:

Nhóm 1: Chính sách của nhà trường

Nhóm 2: Cơ sở vật chất

Nhóm 3: Hỗ trợ của nhà trường

Bảng 3. Kết quả phân tích nhân tố của 10 điều kiện điều kiện về sự hỗ trợ của nhà trường với sinh viên trong các hoạt động gắn kết đào tạo và hoạt động khoa học công nghệ theo CDIO

\begin{tabular}{|l|l|l|l|}
\hline Điều kiện & Nhóm 1 & Nhóm 2 & Nhóm 3 \\
\hline Điều kiện 1 & 0,889 & & \\
\hline Điều kiện 2 & 0,922 & & \\
\hline Điều kiện 3 & 0,879 & & \\
\hline Điều kiện 4 & & 0,871 & \\
\hline Điều kiện 5 & & 0,886 & \\
\hline Điều kiện 6 & & 0,748 & \\
\hline
\end{tabular}

Bảng 4. Mức độ tin cậy của thang đo về năng lực của sinh viên theo mô hình CDIO

\begin{tabular}{|l|l|l|l|}
\hline Năng lực & Năng lực & $\begin{array}{l}\text { Tương } \\
\text { quan với } \\
\text { biến tổng }\end{array}$ & $\begin{array}{l}\text { Hệ số Cronbach's Alpha } \\
\text { nếu loại bỏ biến }\end{array}$ \\
\hline Năng lực 1 & Lên ý tưởng về sản phẩm & 0,694 & 0,834 \\
\hline Năng lực 2 & Thiết kế sản phẩm & 0,632 & 0,857 \\
\hline Năng lực 3 & Triển khai thử nghiệm và hoàn thiện sản phẩm & 0,772 & 0,801 \\
\hline Năng lực 4 & Vận hành các sản phẩm trong thực tế & 0,753 & 0,809 \\
\hline \multicolumn{3}{|c|}{ Độ tin cậy } & 0,864 \\
\hline
\end{tabular}

Bảng 5. Khoảng điểm thang Likert sử dụng trong nghiên cứu

Bảng 5 . Khoảng điểm thang Likert
sử dụng trong nghiên cứu
\begin{tabular}{|l|l|l|}
\hline $\begin{array}{l}\text { Khoảng } \\
\text { điểm }\end{array}$ & $\begin{array}{l}\text { Điều kiện } \\
\text { (Mức độ } \\
\text { đáp ứng) }\end{array}$ & $\begin{array}{l}\text { Năng lực } \\
\text { (Mức độ đáp ứng) }\end{array}$ \\
\hline $1,0-1,8$ & Rất kém & $\begin{array}{l}\text { Hoàn toàn } \\
\text { chưa đáp ứng }\end{array}$ \\
\hline $1,8-2,6$ & Kém & Chưa đáp ứng \\
\hline $2,6-3,4$ & Trung bình & $\begin{array}{l}\text { Đáp ứng } \\
\text { một phần }\end{array}$ \\
\hline $3,4-4,2$ & Khá & Đáp ứng \\
\hline $4,2-5,0$ & Tốt & $\begin{array}{l}\text { Hoàn toàn } \\
\text { đáp ứng }\end{array}$ \\
\hline
\end{tabular}

\begin{tabular}{|c|c|}
\hline Điều kiện 7 & 0,827 \\
\hline Điều kiện 8 & 0,794 \\
\hline Điều kiện 9 & 0,889 \\
\hline Điều kiện 10 & 0,820 \\
\hline
\end{tabular}

Biến phụ thuộc: 4 câu hỏi lấy ý kiến giảng viên và sinh viên về các năng lực của sinh viên theo mô hình CDIO. Độ tin cậy của bộ 4 câu hỏi này được tính theo Cronbach Alpha là 0,864 (độ tin cậy cao) và tương quan giữa các biến đối với biến tổng đều ở trên mức 0,4 cho thấy các biến đều có ảnh hưởng tới năng lực chung của sinh viên theo tiếp cận $\mathrm{CDIO}$ và có thể sử dụng cho các phân tích tiếp theo (Bảng 4).

Với 14 câu hỏi sử dụng thang Likert 5 bậc ở trong nghiên cứu này, nhóm nghiên cứu phân kết quả đánh giá trung bình thành các khoảng đánh giá như ở bảng dưới (Bảng 5):

\section{Phân tích kết quả nghiên cứu}

Từ nghiên cứu các tài liệu, công bố khoa học đi trước, có thể nhận thấy mô hình đào tạo CDIO đáp ứng được yêu cầu của việc đào tạo sinh viên có kiến thức cơ bản, năng lực phẩm chất phù hợp với bối cảnh và khả năng thực hành, vận hành tốt, đáp ứng yêu cầu của nhà tuyển dụng. Sự hình thành các năng lực của sinh viên theo mô hình $\mathrm{CDIO}$ còn phụ thuộc vào các điều kiện phục vụ gắn kết nghiên cứu khoa học với đào tạo theo mô hình $\mathrm{CDIO}$. Vì thế, nhóm tác giả đã đánh giá thực trạng ở 6 cơ sở giáo dục đại học về mức độ đáp ứng của các điều kiện này và ảnh hưởng của chúng tới năng 
lực của sinh viên theo mô hình CDIO. Ngoài kết quả thu được từ phiếu khảo sát, nhóm tác giả cũng đã sử dụng bảng hỏi bán cấu trúc để phỏng vấn một số giảng viên ở 6 cơ sở giáo dục đại học này về thực trạng và một số giải pháp nhằm nâng cao điều kiện gắn kết nghiên cứu khoa học với đào tạo theo mô hình CDIO.

Đối với năng lự của sinh viên theo mô hình CDIO: về đánh giá chung sinh viên đã đạt mức Khá về năng lực (với đánh giá trung bình $3,472 / 5)$, trong đó, năng lực duy nhất được đánh giá ở mức "Trung bình" là "Vận hành các sản phẩm trong thực tể"; 3 tiêu chí còn lại đều đươc đánh giá ở mức "Khá”. Mức độ đạt được của sinh viên về các năng lực giảm dần qua các tiêu chí từ Năng lực 1 tới Năng lực 4 cho thấy sự khó khăn trong việc hình thành năng lực theo CDIO - đặc biệt là năng lực hoàn thiện, vận hành và chuyển giao sản phẩm (Bảng 6).

Với kết quả đánh giá năng lực sinh viên theo mô hình CDIO, nhóm tác giả nhận thấy cần có giải pháp nhằm nâng cao năng lực, phẩm chất của sinh viên - đặc biệt là việc hình thành năng lực hoàn thiện và chuyển giao sản phẩm cho tương xứng với khả năng thu thập thông tin và lên ý tưởng cho sản phẩm.

Bảng 6. Đánh giá của giảng viên và sinh viên về năng lực của sinh viên theo mô hình CDIO

\begin{tabular}{|c|c|c|c|c|c|c|c|c|c|}
\hline \multirow{2}{*}{$\begin{array}{l}\text { Tiêu } \\
\text { chí }\end{array}$} & \multicolumn{3}{|c|}{ Giảng viên } & \multicolumn{3}{|c|}{ Sinh viên } & \multicolumn{3}{|c|}{ Tổng } \\
\hline & $\begin{array}{l}\text { Trung } \\
\text { bình }\end{array}$ & $\begin{array}{l}\text { Độ lệch } \\
\text { chuẩn }\end{array}$ & $\begin{array}{l}\text { Mức độ } \\
\text { đáp ứng }\end{array}$ & $\begin{array}{l}\text { Trung } \\
\text { bình }\end{array}$ & $\begin{array}{l}\text { Độ lệch } \\
\text { chuẩn }\end{array}$ & $\begin{array}{l}\text { Mức độ } \\
\text { đáp ứng }\end{array}$ & $\begin{array}{l}\text { Trung } \\
\text { bình }\end{array}$ & $\begin{array}{l}\text { Độ lệch } \\
\text { chuẩn }\end{array}$ & $\begin{array}{l}\text { Mức độ } \\
\text { đáp ứng }\end{array}$ \\
\hline $\begin{array}{l}\text { Năng } \\
\text { lực } 1\end{array}$ & 3,556 & 0,800 & Khá & 3,562 & 0,738 & Khá & 3,558 & 0,778 & Khá \\
\hline $\begin{array}{l}\text { Năng } \\
\text { lực } 2\end{array}$ & 3,432 & 0,801 & Khá & 3,509 & 0,787 & Khá & 3,460 & 0,797 & Khá \\
\hline $\begin{array}{l}\text { Năng } \\
\text { lực } 3\end{array}$ & 3,371 & 0,842 & $\begin{array}{l}\text { Trung } \\
\text { bình }\end{array}$ & 3,462 & 0,774 & Khá & 3,405 & 0,819 & Khá \\
\hline $\begin{array}{l}\text { Năng } \\
\text { lực } 4\end{array}$ & 3,349 & 0,851 & $\begin{array}{l}\text { Trung } \\
\text { bình }\end{array}$ & 3,369 & 0,822 & $\begin{array}{l}\text { Trung } \\
\text { bình }\end{array}$ & 3,356 & 0,841 & $\begin{array}{l}\text { Trung } \\
\text { bình }\end{array}$ \\
\hline
\end{tabular}

Nguồn: Dữ liệu khảo sát thuộc đề tài khoa học và công nghệ độc lập cấp Quốc gia, mã số ĐTĐLXH - 12/18.

Để cụ thể hóa giải pháp, nghiên cứu đã đánh giá mối liên hệ giữa năng lực của sinh viên với thực trạng điều kiện phục vụ gắn kết nghiên cứu khoa học với đào tạo theo mô hình CDIO thông qua hệ số tương quan Pearson (ở đây, nhóm tác giả sử dụng thêm 1 biến "Năng lực chung" được tính bằng giá trị trung bình của 4 biến năng lực). Kết quả cho thấy, tất cả các điều kiện đều có ảnh hưởng tới sự hình thành năng lực của sinh viên theo mô hình CDIO (hệ số tương quan lớn hơn 0,2 ở mức ý nghĩa 99\%) - đặc biệt các điều kiện đều có tương quan ở mức trung bình với biến tổng (hệ số tương quan của điều kiện với năng lực chung là trên 0,25$)$. Trong đó, điều kiện về "Cơ sở vật chất, trang thiết bị (Điều kiện 5)" và "Học liệu (Điều kiện 6)" được đối tượng khảo sát đánh giá có ảnh hưởng lớn nhất tới năng lực chung của sinh viên theo tiếp cận $\mathrm{CDIO}$ với hệ số tương quan Pearson lần lượt là 0,333 và 0,336 . Qua đó có thể thấy, điều kiện cơ sở vật chất là một yếu tố tiên quyết trong quá trình hình thành và nâng cao năng lực của sinh viên. Cùng với đó, năng lực được đánh giá thấp nhất của sinh viên là "Vận hành các sản phẩm trong thực tế (Năng lực 4)" có hệ số tương quan lớn nhất với "Sự hỗ trợ của nhà trường trong việc giúp sinh viên thương mại hóa/chuyển giao sản phẩm (Điều kiện 10)" cho thấy để nâng cao năng lực của sinh viên theo tiếp cận CDIO thì ngoài nâng cao chất lượng cơ sở vật chất, các cơ sở giáo dục đào tạo cần chú ý tới công tác hỗ trợ sinh viên hoàn thiện các bước sau của CDIO (ngoài hình thành, phân tích ý tưởng, cơ sở giáo dục đại học cần tăng cường hỗ trợ sinh viên phát triển, hoàn thiện, hướng tới thương mại hóa sản phẩm) (kết quả đánh giá chi tiết trong Bảng 5). 
Bảng 7. Hệ số tương quan Pearson của năng lực sinh viên đối với điều kiện phục vụ gắn kết nghiên cứu khoa học với đào tạo theo mô hình $\mathrm{CDIO}$ ở trường đại học

\begin{tabular}{|l|l|l|l|l|l|}
\hline & Năng lực 1 & Năng lực 2 & Năng lực 3 & Năng lực 4 & $\begin{array}{l}\text { Năng lực } \\
\text { chung }\end{array}$ \\
\hline Điều kiện 1 & 0,246 & 0,256 & 0,246 & 0,259 & 0,299 \\
\hline Điều kiện 2 & 0,264 & 0,251 & 0,256 & 0,266 & 0,308 \\
\hline Điều kiện 3 & 0,242 & 0,221 & 0,236 & 0,263 & 0,287 \\
\hline Điều kiện 4 & 0,23 & 0,256 & 0,228 & 0,215 & 0,275 \\
\hline Điều kiện 5 & 0,273 & 0,29 & 0,268 & 0,271 & 0,327 \\
\hline Điều kiện 6 & 0,274 & 0,285 & 0,264 & 0,278 & 0,327 \\
\hline Điều kiện 7 & 0,25 & 0,235 & 0,239 & 0,236 & 0,285 \\
\hline Điều kiện 8 & 0,222 & 0,201 & 0,204 & 0,236 & 0,256 \\
\hline Điều kiện 9 & 0,232 & 0,246 & 0,25 & 0,272 & 0,298 \\
\hline Điều kiện 10 & 0,222 & 0,239 & 0,267 & 0,306 & 0,309 \\
\hline
\end{tabular}

Nguồn: Dữ liệu khảo sát thuộc đề tài khoa học và công nghệ độc lập cấp Quốc gia, mã số ĐTĐLXH - 12/18.

Về các điều kiện phục vu gắn kết nghiên cứu khoa hoc với đào tạo theo mô hìn CDIO ơ trường đại hoc: Kết quả khảo sát cho thấy, đối tượng khảo sát có đánh giá điều kiện phục vụ gắn kết nghiên cứu khoa học với đào tạo theo mô hình CDIO ở trong trường đại học nhìn chung đã đáp ứng được nhu cầu với mức đánh giá chung cho 10 tiêu chí là 3,46/5 (ở mức Đáp ứng).

Trong đó, các chính sách của nhà trường đối với hoạt động của sinh viên bao gồm: chính sách về học bổng, quỹ hỗ trợ sinh viên nghiên cứu khoa học; chính sách hỗ trợ nghiên cứu khoa học của sinh viên và chính sách hỗ trợ sinh viên tham gia thực hành, thực tập tại các doanh nghiệp đã được đánh giá đáp ứng với nhu cầu của đối tượng khảo sát với mức đánh giá trung bình 3,42/5 (mức Đáp ứng). Tuy nhiên, tiêu chí "Chính sách hỗ trợ sinh viên tham gia thực hành, thực tập tại các doanh nghiệp (Điều kiện 3)" còn chưa được đánh giá cao (3,33/5 - Đáp ứng một phần) - đặc biệt giảng viên chỉ đánh giá ở mức $3,11 / 5$. Nhằm làm rõ hơn vấn đề chính sách hỗ trợ sinh viên tham gia thực tập tại doanh nghiệp ở các cơ sở giáo dục đại học được khảo sát, nhóm tác giả đã thực hiện phỏng vấn một số giảng viên về thực trạng và ý kiến của giảng viên nhằm nâng cao sự phối hợp nhà trường - doanh nghiệp. Kết quả phỏng vấn cho thấy hầu hết các giảng viên đều đồng ý chính sách hiện tại còn nhiều bất cập, ngoài ra, phương thức phối hợp giữa cơ sở giáo dục đại học - doanh nghiệp còn chưa tốt. Cụ thể, một giảng viên được phỏng vấn chia sẻ: “... Để sinh viên có môi truờng tiếp xúc với thực tế, cần phải đẩy mạnh hơn nữa chính sách hỗ trọ sinh viên tham gia thưc hành, thwe tập tại các doanh nghiệp, đặc biệt, phải có gắn kết nhịp nhàng giữa nhà trường và doanh nghiẹp, giúp sinh viên được trải nghiệm thực tiễn dựa trên chính nhũng kiến thức đã hoc, ...". Đồng quan điểm đó, một giảng viên khác cũng cho ý kiến: “... Kết hợp hoạt động của các doanh nghiệp, nhu cầu đào tạo xã hội, để sinh viên thưc tập, thưc hành nghiên cưu, làm khóa luận tốt nghiệp theo định huớng về yêu cầu doanh nghiẹp cùng với sụ hố trợ tù thầy cô, nhà trường". Các ý kiến này đều cho thấy, giảng viên được phỏng vấn đã có ý tưởng về việc phối hợp giữa cơ sở giáo dục đại học - doanh nghiệp thông qua việc giúp sinh viên tiếp cận, làm nghiên cứu và có thể đưa ra sản phẩm trong quá trình thực hành, thực tập tại doanh nghiệp cho phù hợp với yêu cầu của doanh nghiệp và thực tiễn. Ngoài ra, đối với "Chính sách hỗ trợ sinh viên tham gia nghiên cứu khoa học (Điều kiện 2)" (1 trong 3 điều kiện có ảnh hưởng lớn nhất tới sự hình 
thành năng lực chung của sinh viên với hệ số tương quan 0,314 ), đánh giá chung của 2 nhóm đối tượng khảo sát đánh giá ở mức Đáp ứng. Tuy nhiên, đánh giá riêng của giảng viên cho thấy điều kiện này mới đạt mức "Đáp ứng một phần" và vẫn cần có sự quan tâm tới từ nhà trường không chỉ từ tài chính mà còn là tạo điều kiện tiếp xúc với các nhà khoa học có nhiều năm kinh nghiệm (có thể thông qua tham gia vào các nhóm nghiên cứu mạnh của nhà trường). Đồng quan điểm đó, một giảng viên được phỏng vấn đã cho biết, sinh viên có thể được hỗ trợ nghiên cứu thông qua việc “... tham gia nghiên cúu theo lab, nhóm phục vu đề tài nghiên cứu khoa học và chuyển giao công nghệ với giảng viên để bồi dương năng lự nghiên cứu gắn liền với thục tế, phục vu xã hội, cộng đồng,...; nhà trường có thể tổ chức cuộc thi ý tương startup, cuôc thi khoa hoc công nghệ về phát triển sản phẩm do tập đoàn, doanh nghiệp tài tro, ,..."

Đối với nhóm điều kiện co sở vật chất, các tiêu chí đều được đánh giá ở mức đáp ứng trong cả 3 tiêu chí với mức đánh giá thấp nhất là $3,60 / 6$ đối với "Cơ sở vật chất và trang thiết bị (Điều kiện 5)" cho thấy trong 6 cơ sở giáo dục đại học được khảo sát, trang thiết bị đã đáp ứng được nhu cầu sử dụng của giảng viên và sinh viên, tuy nhiên, vẫn còn cần cải thiện nhằm phục vụ tốt hơn công tác gắn kết đào tạo và hoạt động khoa học công nghệ. Khi phỏng vấn giảng viên về thực trạng cơ sở vật chất của đơn vị công tác, một giảng viên được phỏng vấn cho biết: “... sinh viên có thể được tiếp cận các nguồn học liệu chuyên ngành tại các phòng thi nghiệm riêng của các nhóm nghiên cưu, nhung số lượng hạn chế. Hơn nũa, thu viện của đơn vị không cấp được các tài khoản để truy cập và tải các tài liệu là các tạp chi khoa hoc chuyên ngành, đa phần lấy qua nguồn không chính thống, còn thu viện mở vào các giờ hành chinh làm khó sinh viên đam mê học tập,...". Điều này cho thấy, các đơn vị đã chú ý đầu tư tới học liệu phục vụ học tập, thực hành và nghiên cứu nhưng học liệu số còn hạn chế khiến cho việc tiếp cận của sinh viên còn gặp nhiều khó khăn. Ngoài ra, giảng viên cũng cho ý kiến về trang thiết bị của đơn vị "Trang thiết bị còn yếu và chưa đáp ứng nhu cầu của sinh viên; Co chế quản lý trang thiết bị còn bị hành chính hóa, nên sư tiếp cận của sinh viên bị ảnh hưởng; Tài chính đề mua sắm hóa chất, nguyên vật liệu tiêu hao giúp sinh viên sử dụng trang thiết bi chura có,...". Để cải thiện về điều kiện cơ sở vật chất, giảng viên khác cho ý kiến “... Khuyến khich sinh viên, học viên cao học, nghiên cưu sinh tham gia; Tăng hỗ trợ tài chính; Khuyến khich sư tham gia của doanh nghiẹp, tăng tốc độ và thủ tục thanh toán, tài chính; Có nhiều chính sách cải thiện, nâng cao cơ sở hạ tầng phuc vu đào tạo, nghiên cứu khoa học (nhu thu hút hố trợ tù cưu sinh viên, doanh nghiệp cho phòng thí nghiệm, trang thiết bi),..." để có thể tận dụng sự hỗ trợ của doanh nghiệp giúp nâng cao điều kiện cơ sở vật chất (trang thiết bị, phòng thí nghiệm).

Đối với nhóm điều kiện về sự hỗ trợ của nhà trường với sinh viên trong các hoạt động gắn kết đào tạo và hoạt động khoa học công nghệ theo CDIO, chỉ có "Sự hỗ trợ của nhà trường trong việc giúp sinh viên hình thành ý tưởng nghiên cứu (Điều kiện 7)" được đánh giá Đáp ứng (mức đánh giá 3,41/5) - còn đối với 3 tiêu chí còn lại chỉ đạt mức Đáp ứng một phần; cùng với đó, mức đánh giá thấp dần qua các nhóm tiêu chí theo hướng $\mathrm{CDIO}$ từ lên ý tưởng - phân tích, đánh giá ý tưởng - hoàn thiện sản phẩm - thương mại hóa và triển khai sản phẩm cho thấy: i) các cơ sở giáo dục đại học được khảo sát đã chú ý tới công tác hỗ trợ sinh viên triển khai hoạt động nghiên cứu khoa học theo tiếp cận CDIO nhưng khả năng hỗ trợ giảm dần ở các bước sau dẫn đến việc thực hiện hoàn thiện, vận hành và chuyển giao, thương mại hóa sản phẩm còn gặp nhiều khó khăn - có thể nhận thấy thông qua kết quả đánh giá năng lực của sinh viên theo CDIO; và ii) mức độ đáp ứng của sự hỗ trợ còn chưa cao - đặc biệt là trong đánh giá của giảng viên (mức đánh giá trung bình chỉ đạt 3,15/5 - thấp nhất trong 4 nhóm điều kiện). Để thúc đẩy sự hỗ trợ, một Phó Giáo sư được khảo sát đã cho ý kiến: "Cần tổ chức đào tạo ở dạng project base có liên quan đến nhu cầu đặt hàng từ doanh nghiệp. Kết nối kênh liên lạc nhằm thúc đẩy hợp tác giữa giảng viên và doanh nghiệp để giảng viên có thể định hướng 
nghiên cứu khoa học cho sinh viên gắn liền với thực tế xã hội, với nhu cầu của doanh nghiệp". Điều này cho thấy sự kết nối các sản phẩm của sinh viên với thực tế xã hội và nhu cầu của doanh nghiệp sẽ giúp sinh viên chủ động nhận được sự hỗ trợ hoàn thiện và thương mại hóa sản phẩm (Bảng 8).

Kết quả khảo sát thông qua bảng hỏi cho thấy, về căn bản các điều kiện phục vụ gắn kết nghiên cứu khoa học với đào tạo theo mô hình CDIO ở trường đại học đã đáp ứng được yêu cầu của giảng viên và sinh viên tại 6 cơ sở giáo dục đại học được khảo sát. Tuy nhiên, các cơ sở đào tạo còn có thể cải thiện tốt hơn tiêu chí "Chính sách hỗ trợ sinh viên tham gia thực hành, thực tập tại các doanh nghiệp (Điều kiện 3)" nhằm giúp gắn hoạt động đào tạo, nghiên cứu khoa học của sinh viên với thực tiễn công việc sau khi ra trường và tăng trải nghiệm thực tế của sinh viên, qua đó nâng cao năng lực "Triển khai thử nghiệm và hoàn thiện sản phẩm (Năng lực 3)" và "Vận hành các sản phẩm trong thực tế (Năng lực 4)".

Bảng 8 . Đánh giá của giảng viên và sinh viên đối với điều kiện phục vụ gắn kết nghiên cứu khoa học với đào tạo theo mô hình CDIO

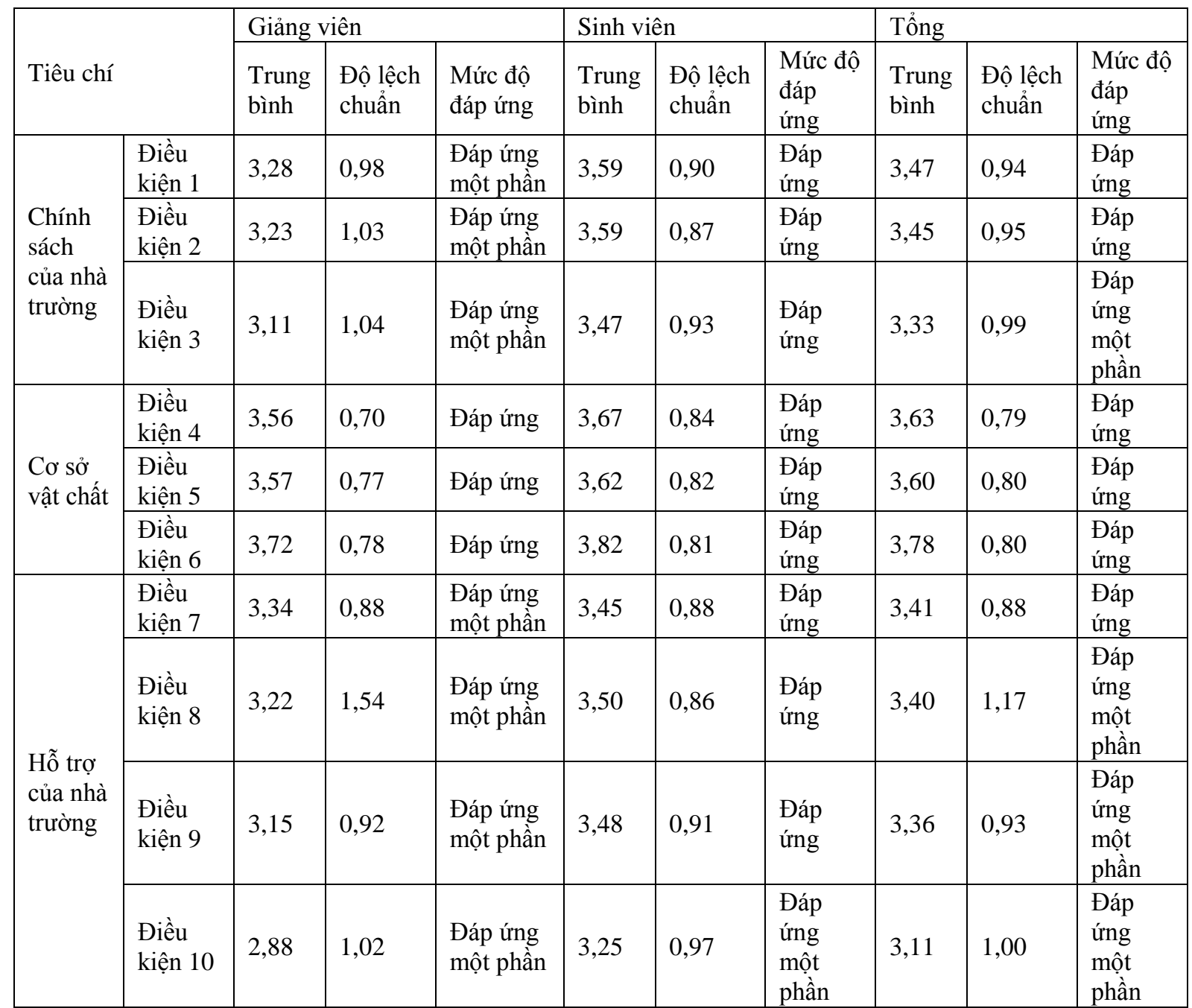

Nguồn: Dữ liệu khảo sát thuộc đề tài khoa học và công nghệ độc lập cấp Quốc gia, mã số ĐTĐLXH - 12/18. 
Cùng với đó, cần có giải pháp nâng cao điều kiện về cơ sở vật chất - trang thiết bị cũng như học liệu phục vụ cho đào tạo và nghiên cứu vì đây là 2 điều kiện có ảnh hưởng lớn nhất tới năng lực chung của sinh viên theo mô hình CDIO. Ngoài ra, công tác phát triển quỹ hỗ trợ sinh viên nghiên cứu khoa học và chính sách hỗ trợ sinh viên tham gia nghiên cứu khoa học cũng cần được quan tâm - tuy điều kiện này đã được đánh giá ở mức Đáp ứng nhưng với đánh giá của giảng viên thì mới chỉ đạt mức Đáp ứng một phần yêu cầu thực tế.

\section{Các giải pháp về các hoạt động nghiên cứu khoa học nhằm nâng cao năng lực sinh viên trong đào tạo theo mô hình CDIO}

Để giúp sinh viên nâng cao các năng lực về hình thành ý tưởng sáng tạo, thiết kế sản phẩm, triển khai thực hiện chế tạo sản phẩm và vận hành sản phẩm trong thực tiễn, các trường đại học đào tạo theo mô hình $\mathrm{CDIO}$ cần chú ý tới các biện pháp sau:

Thư nhất, xây dựng và hoàn thiện hệ thống chinh sách hố trợ sinh viên nghiên cúu khoa hoc phù hơp với đặc thù của trương đại học.

Các trường đại học cần xây dựng hệ thống chính sách và thực hiện đồng bộ giúp sinh viên hình thành được các năng lực đáp ứng nhu cầu thị trường lao động. Ngoài việc nghiên cứu cùng các thầy cô giáo và các cán bộ nghiên cứu trong trường đại học, cần cho phép sinh viên được chủ trì đề tài nghiên cứu khoa học cấp cơ sở hay chủ trì một nhiệm vụ liên quan tới chuyên ngành của sinh viên. Các trường đại học cần tăng cường công tác phối hợp giữa các khoa, phòng ban, trung tâm, đoàn thanh niên, hội sinh viên để hỗ trợ sinh viên nghiên cứu khoa học. Một số chính sách như: tài trợ kinh phí và hỗ trợ trang thiết bị cho các ý tưởng sinh viên đề xuất nghiên cứu; xây dựng chính sách trả lương cho sinh viên từ các đề tài mà thầy cô hướng dẫn là chủ nhiệm đề tài các cấp; cộng điểm thành tích cho sinh viên đạt giải nghiên cứu khoa học; đưa yêu cầu về đăng bài báo, báo cáo khoa học hoặc sản phẩm nghiên cứu khoa học là chuẩn đầu ra của môn học là những chính sách cần được xem xét và từng bước áp dụng.

Thư hai, phát triến quỹ hố trọ sinh viên nghiên cúu khoa học.

Hoạt động khoa học và công nghệ hiện nay một phần được hỗ trợ kinh phí bởi Quỹ phát triển khoa học và công nghệ quốc gia. Với các hoạt động được triển khai, nhiều công trình nghiên cứu khoa học đã được đẩy mạnh, phát triển. Về phía các trường đại học, có thể nói mỗi trường đại học là một trung tâm nghiên cứu khoa học phát triển ngành nghề đào tạo trên mỗi lĩnh vực nhất định. Để hoạt động hiệu quả, cần thành lập Quỹ phát triển khoa học công nghệ hoặc Quỹ hỗ trợ sinh viên nghiên cứu khoa học nhằm đảm bảo sự linh hoạt và chủ động trong phân bổ, sử dụng kinh phí phục vụ nghiên cứu. Để thúc đẩy định hướng hoạt động và huy động nguồn kinh phí cho Quỹ hỗ trợ sinh viên nghiên cứu khoa học, các trường cần kết hợp chặt chẽ giữa nghiên cứu khoa học với giảng dạy, tăng cường hợp tác quốc tế, tận dụng, huy động các nguồn tài trợ, hỗ trợ của các quỹ trong và ngoài nước về nghiên cứu khoa học. Bên cạnh đó cần lưu ý khai thác các hỗ trợ, đặt hàng từ doanh nghiệp, đơn vị sử dụng lao động để đa dạng hóa nguồn thu cho Quỹ.

Thứ ba, đầu tu co sở vật chất và trang thiết bị cho thực hành và nghiên cúu khoa họ.

Hoạt động quản lý trên mọi lĩnh vực đều hướng tới mục tiêu nâng cao chất lượng. Thực tế cho thấy, cơ sở đào tạo nào có đơn vị quản lý nghiên cứu khoa học mạnh thì ở đó hoạt động nghiên cứu khoa học phát triển mạnh, thu hút được nhiều đầu tư, hỗ trợ. Vì thế, cần phải quan tâm phát triển hệ thống nhân lực quản lý hoạt động nghiên cứu khoa học, xây dựng quy trình, quy chế và các tiêu chí đảm bảo chất lượng nghiên cứu khoa học trong cơ sở đào tạo. Về cơ sở vật chất, hiện nay chỉ một số cơ sở đào tạo đã được đầu tư về trang thiết bị thực hành và nghiên cứu khoa học, nhất là về lĩnh vực khoa học tự nhiên. Còn lại, đa số các cơ sở đào tạo chưa được quan tâm đầu tư đúng mức cho hoạt động nghiên cứu khoa học. Vì vậy, cần đầu tư phát triển về cơ sở vật chất và trang thiết bị cho 
thực hành, nhưng ngược lại, mỗi cơ sở đào tạo phải không ngừng quán triệt đội ngũ giảng viên, cán bộ quản lý, sinh viên tăng cường các hoạt động sử dụng, ứng dụng các phòng thí nghiệm, thực hành, các thiết bị hỗ trợ nghiên cứu, thử nghiệm. Đồng thời, đưa tiêu chí về việc thiết kế, triển khai, vận hành (DIO) trực tiếp tại các phòng thí nghiệm, thực hành vào chuẩn đầu ra để sinh viên chủ động thực hiện.

Thư tu, tăng cuờng đầu tu học liệu cập nhật cho sinh viên, đặc biệt là các học liệu liên quan đến thực hành, thưc tập, nghiên cứu khoa học.

Các kết quả nghiên cứu cho thấy sinh viên hứng thú hơn với việc khai thác học liệu qua các phương tiện và thiết bị điện tử. Xu thế quốc tế cho thấy đây cũng là một phương thức hỗ trợ nghiên cứu khoa học và học tập hiệu quả hiện nay tại các trường đại học. Do đó, để thúc đẩy hoạt động nghiên cứu khoa học trong sinh viên, đảm bảo hiệu quả tiến trình đào tạo theo CDIO và nâng cao năng lực cho người học, các trường đại học cần có kế hoạch số hoá học liệu và xây dựng hệ thống học liệu điện tử đa dạng, phong phú, giúp sinh viên dễ dàng truy cập và sử dụng. Để triển khai giải pháp này, ngoài nỗ lực của trung tâm thông tin thư viện trong việc số hoá tài liệu sẵn có, cần có sự tham gia của các nhà khoa học và giảng viên trong việc chia sẻ, đóng góp giáo trình, bài giảng, sách chuyên khảo của mình để tạo lập nguồn học liệu nội sinh đảm bảo được cả chất lượng và số lượng. Bên cạnh đó, để tiết kiệm chi phí cũng như giúp đa dạng hoá nguồn tài nguyên học liệu số, các trường đại học cũng cần liên kết, phối hợp trong tạo lập học liệu số hoặc mua sắm các cơ sở dữ liệu học thuật quốc tế để có cơ sở học liệu dùng chung, qua đó tăng cường diện truy cập học liệu cho sinh viên học tập và nghiên cứu. Việc cùng hợp tác và mua quyền truy cập theo nhóm trường đối với các cơ sở dữ liệu học thuật quốc tế sẽ giúp các thư viện tiếp cận được nhiều nguồn thông tin hơn với chi phí rẻ hơn. Hầu hết các nhà cung cấp dữ liệu đều có chính sách khuyến khích mua bản quyền truy cập cơ sở dữ liệu theo nhóm dành cho các thư viện.
Thư năm, hỗ trọ sinh viên tham gia thưcc hành, thực tập tại các doanh nghiệp.

Trước hết, nhà trường cần xây dựng chương trình đào tạo gắn liền với thực tiễn nghề nghiệp, lấy ý kiến rộng rãi của các bên liên quan, đặc biệt là ý kiên của nhà sử dụng lao động để sinh viên đáp ứng nhu cầu thị trường lao động. Nhà trường cần kết nối với các doanh nghiệp, ký kết biên bản ghi nhớ hợp tác với doanh nghiệp, trong đó cam kết hỗ trợ sinh viên thực hành, hỗ trợ nhà trường trang thiết bị thực hành, phương tiện dạy học thực hành; tạo điều kiện cho các giảng viên và sinh viên đến doanh nghiệp học tập kinh nghiệm, trao đổi kiến thức, tiếp cận công nghệ mới, nâng cao trình độ; có thể triển khai chương trình thực tập có lương để khuyến khích sinh viên tích cực tham gia. Nhà trường cần thành lập trung tâm hỗ trợ thực tập cho sinh viên nhằm cung cấp cho sinh viên các thông tin cần thiết và giới thiệu các em với các doanh nghiệp cũng như tiếp nhận các thông tin phản hồi từ các doanh nghiệp. Việc triển khai quy trình hoạt động thực tập nhằm phối hợp chặt chẽ và hiệu quả giữa nhà trường, giảng viên với các cơ sở thực tập về thời gian và nội dung thực tập, kết quả thực tập tại các cơ sở thực tế phải được đánh giá khách quan và đảm bảo được chất lượng của hoạt động thực tập. Nhà trường tập huấn cho giảng viên kĩ năng hướng dẫn sinh viên tham gia thực tập, đánh giá và cải tiến sau mỗi kỳ thực tập để công tác thực tập đạt hiệu quả cao hơn.

Thư sáu, hỗ trợ sinh viên trong việc vận hành các sản phẩm trong thực tế, chuyển giao sản phẩm tới thị truờng.

Để làm được việc này, nhà trường cần kết nối với doanh nghiệp để có cơ sở vật chất và trang thiết bị đầy đủ hơn nhằm vận hành sản phẩm. Các trường đại học cần thành lập bộ phận kết nối doanh nghiệp với nhà trường. Trường đại học liên kết với doanh nghiệp theo hai hình thức: thứ nhất, kết nối để các doanh nghiệp chuyển giao công nghệ cho nhà trường; thứ hai, nhà trường (hoặc một nhóm trường) có thể trở thành cổ đông của các doanh nghiệp. Trong xu thế tự chủ của các trường đại học, một 
số trường đại học đủ điều kiện để thành lập các doanh nghiệp trực thuộc. Doanh nghiệp của nhà trường có nhiệm vụ phát triển các mối quan hệ hợp tác với các tổ chức, các doanh nghiệp bên ngoài nhà trường và đây cũng chính là nơi chuyển giao sản phẩm do sinh viên thiết kế và sản xuất tới thị trường tiêu dùng sản phẩm.

\section{Kết luận}

Các yếu tố liên quan đến hoạt động nghiên cứu khoa học tại các trường đại học như các chính sách hỗ trợ sinh viên; cơ sở vật chất và học liệu phục vụ nghiên cứu khoa học; sự hỗ trợ của nhà trường đối với sinh viên đều là các yếu tố có ảnh hưởng lớn đến năng lực CDIO của sinh viên gồm năng lực hình thành ý tưởng, thiết kế, triển khai và vận hành sản phẩm. Kết quả cho thấy các yếu tố có ảnh hưởng nhiều nhất đến năng lực của sinh viên là nhóm yếu tố về cơ sở vật chất và trang thiết bị phục vụ thực hành, thực tập và nghiên cứu khoa học; tiếp đến là nhóm yếu tố về sự hỗ trợ của nhà trường trong bốn giai đoạn $\mathrm{CDIO}$ và ảnh hưởng ít nhất đến năng lực sinh viên là nhóm yếu tố về chính sách của nhà trường. Nhìn chung cả 4 năng lực của sinh viên đều được đánh giá ở mức khá cao và có sự phân biệt giữa các trường đại học. Năng lực của sinh viên được đánh giá cao nhất là năng lực Hình thành ý tưởng, tiếp đến là năng lực Thiết kế sản phẩm và đánh giá thấp nhất là năng lực Vận hành các sản phẩm và chuyển giao trong thực tế. Để năng cao năng lực $\mathrm{CDIO}$ của sinh viên, các trường cần triển khai thực hiện sáu giải pháp đã nêu ở trên theo lộ trình hợp lý đối với mỗi trường đại học.

\section{Lời cảm ơn}

Nghiên cứu được tài trợ bởi đề tài khoa học và công nghệ độc lập cấp Quốc gia, mã số ĐTĐLXH - 12/18.

\section{Tài liệu tham khảo}

[1] Vietnam Central Executive Committee, Resolution No. 29-NQ/TW on Fundamental and
Comprehensive Renovation of Education and Training, Meeting the Requirements of Industrialization and Modernization in the Conditions of Socialist-oriented Market Economy and International Integration, 2013.

[2] T. T. Hoai, N. T. Ba, Studying the Competencies of University Graduates Responding to Industrial Revolution 4.0. VNU Journal of Science: Education Research, Vol. 36, No. 1, 2020, pp. 2588-1159, https://doi.org/10.25073/2588-1159/vnuer.4363.

[3] World Economic Forum, The Future of Jobs Employment, Skills and Workforce Strategy for the Fourth Industrial Revolution Executive Summary, http://www3.weforum.org/docs/WEFFuture-of-Jobs.pdf/, 2016 (accessed on: March $\left.03^{\text {th }}, 2021\right)$.

[4] F. Hecklau, M. Galeitzke, S. Flachs, H. Kohl, Holistic Approach for Human Resource Management in Industry 4.0, Procedia Cirp 54, 2016, pp. 1-6.

[5] World Economic Forum, These are the Top 10 Job Kills of Tomorrow - and How Long it Takes to Learn them,

https://www.weforum.org/agenda/2020/10/top-10 work-skills-of-tomorrow-how-long-it-takes-to-learnthem/, 2020 (accessed on: March 03 ${ }^{\text {th }}, 2021$ ).

[6] BRICS Skill Development Working Group, Skill Development for Industry 4.0, Whitepaper Summary, BRICS Council, 2106.

[7] S. Luckman, Craft and the Creative Economy, Springer, 2015.

[8] T. L. Tran, S. Marginson et al., Higher Education in Vietnam: Flexibility, Mobility and Practicality in the Global Knowledge Economy, Palgrave Macmillan, 2014.

[9] T. L. A. Vu, Building CDIO Approach Training Programmes Against Challenges of Industrial Revolution 4.0 for Engineering and Technology Development. Int. J. Eng, Vol. 11, No. 7, 2018, pp. 129-1148.

[10] E. T. Pascarella, P. T. Terenzini, How College Affects Students: A third Decade of Research, San Francisco, CA: Jossey-Bass, 2005.

[11] R. S. Hathaway, B. A. Nagda, S. R. Gregerman, The Relationship of Undergraduate Research Participation to Graduate and Professional Education Pursuit: An Empirical Study, Journal of College Student Development, Vol. 43, No. 5, 2002, pp. 614-631.

[12] E. Nnadozie, J. Ishiyama, J. Chon, Undergraduate Research Internships and Graduate School Success, Journal of College Student Development, Vol. 42, No. 2, 2001, pp. 145-156. 
[13] C. Justice, J. Rice, W. Warry, S. Inglis, S. Miller, S. Sammon, Inquiry in Higher Education: Reflections and Directions on Course Design and Teaching Methods, Innovative Higher Education, Vol. 31, No. 4, 2007, pp. 201-214.

[14] J. F. Volkwein, D.A. Carbone, The Impact of Departmental Research and Teaching Climates on Undergraduate Growth and Satisfaction, Journal of Higher Education, Vol. 65, No. 2, 1994, pp. 147-159.

[15] C. Gonzalez, Undergraduate Research, Graduate Mentoring, and the University's Mission, Science, Vol. 293, No. 5535, 2001, pp. 1624-1626.

[16] J. Wonglimpiyarat, The Innovation Incubator, University Business Incubator and Technology Transfer Strategy: The Case of Thailand, Technology in Society, Vol. 46, 2016, pp. 18-27.

[17] P. U. Lijie, Innovation and Entrepreneurship Education at Nanjing University, Asian University Forum, Mogolia, 6 June, 2017.

[18] R. Brown, Mission Impossible? Entrepreneurial Universities and Peripheral Regional Innovation Systems, Industry and Innovation, Vol. 23, No. 2, 2016, pp. 1-17.

[19] N. K. Dung, P. T. Huong, The Reality of University-business Cooperation in Vietnam, Ho Chi Minh City University of Education Journal of Science, Vol. 14, No. 4, 2017, pp. 29-41.

[20] T. T. H. Mai, Training Asociation between Universities and Businesses in Vietnam, VNU Journal of Science: Economics-Law, Vol. 24, 2008, pp. 30-34.

[21] B. D. Tho, Model of Linking Scientific Research and Training, Workshop Proceedings: Combining
Training with Scientific Research and Technology Transfer in Higher Education Institutions, Da Nang, 2017 (in Vietnamese).

[22] CDIO Organization, http://www.cdio.org/cdioOrganization (accessed on: March $13^{\text {th }}, 2021$ ).

[23] E. F. Crawley, J. Malmqvist, S. Östlund, D. R. Brodeur, K. Edström, The CDIO Approach, In: Rethinking Engineering Education, Springer, Cham, 2014, pp. 11-45, https://doi.org/10.1007/978-3-319-05561-9-2.

[24] D. T. M. Trinh, N. Q. Chinh, N. H. Loc, P. C. Bang, H. T. Nhut, Design and Develop Training Programs to Meet Learning Outcomes, 2012 (in Vietnamese).

[25] P. X. Nha, V. A. Dung, Designing and Implementing Graduate and Postgraduate Training Programs by Approaching CDIO Methods, Vietnam National University Press, Hanoi, 2011 (in Vietnamese).

[26] H. T. H. Yen, Improving the Financial Mechanism for Science and Technology Activities in Universities in Vietnam, PhD Thesis in Economics, National Economics University, 2008.

[27] Scientific Research Student Award 2020, https://moet.gov.vn/giaoducquocdan/khoa-hoc-vacong-nghe/Pages/Default.aspx?ItemID=7003/, 2020 (accessed on: March 13 ${ }^{\text {th }}, 2021$ ).

[28] H. T. Nhut, D. T. M. Trinh, Reform and Build Technical Training Program According to CDIO Approach, Vietnam National University Press, Ho Chi Minh, 2010 (in Vietnamese).

[29] Ho Chi Minh City National University, National CDIO Conference 2012, 2012 (in Vietnamese). 